\title{
Application of Individual Pitch Controller for Flicker Reduction on Variable Speed Wind Turbines
}

\author{
Haiyun Wang ${ }^{1,2}$ \\ 1 Electrical Engineering Institute \\ Xi'an Jiaotong University \\ Xi'an, China \\ wanghaiyunyun@yahoo.com.cn
}

\author{
Weiqing Wang ${ }^{2}$ \\ 2 Electrical Engineering Institute \\ Xinjiang University \\ Urumqi, China \\ wwq59@xju.edu.cn
}

\author{
Liang $\operatorname{Bin}^{3}$ \\ 3 Technical Research Department \\ Xinjiang Goldwind Science \& Technology,CO., Ltd. \\ Urumqi, China \\ liangbin@goldwind.cn
}

\begin{abstract}
This article reviews the design of algorithms for individual pitch control in the case of variable speed turbines. The aim of the designed control algorithm is to improve the power quality and to reduce voltage flicker. A simulation model of variable speed wind turbine was developed with the simulation tool of PSCAD/EMTDC. This article compared the individual pitch action and the collective pitch action, which is the same for all three blades, is calculated by means of a standard classical PIbased controller. The simulation result indicates that compared with the flicker coefficient of PI controlled wind turbine, the variable-speed wind turbines equipped with individual pitch controller, exhibit good behavior with respect to output power and voltage flicker, especially for $3 P$ frequency reduction. Thereby, the variable-speed wind turbine with individual pitch controller will produce lower voltage flicker.
\end{abstract}

Keywords-flicker; power quality; wind generator system; permanent maget motor; simulation

\section{INTRODUCTION}

In recent years the trend has been moved from installations with a few wind turbines to the planning of large wind farms with more than hundreds of MW of capacity. This increased and concentrated penetration makes the power network vulnerable to the wind energy production. The two utilities responsible in Denmark for power supply networks, Eltra and Elkraft, have issued requirements[1] that focus on the influence of wind farms on grid stability and power quality, and on the control capabilities of wind farms. Moreover, national standards for power quality of wind turbines have recently been supplemented by a new standard for measurement and assessment of power quality of grid connected wind turbines, namely IEC 61400-21[2]. Among the great increase of the wind energy generation within the electricity grid the complexity of the wind turbine performance on turbulent winds is becoming of vital interest in technical, economical and scientific aspects. One of the current challenges in wind energy production is to estimate the power fluctuation and voltage flicker of the wind turbine properly.
Blade pitch control is primarily used to limit the aerodynamic power in above-rated wind speeds, in order to keep the turbine within its design limits. In variable speed turbines, the control algorithms have a major influence on the power quality produced by the wind turbine. As the size of wind turbines increases, the controller design becomes increasingly important. Increasing the rotor diameters also increases asymmetric loading of the rotor blades[3,4]. Many control techniques have been put forward for the purpose which includes individual pitch control [5-7].

Individual pitch control is also likely to be of major interest as turbines become larger and more flexible. For a three-bladed rotor, with the result that the hub and the rest of the structure will experience the harmonics at $3 \mathrm{P}, 6 \mathrm{P}$, etc, which is mainly factors caused the power fluctuation and voltage flicker. The aim of the individual pitch control is to counteract the $3 \mathrm{P}$ harmonics and the asymmetrical rotor loading caused by wind shear, upflow, yaw misalignment and tower shadow.

In the paper, the importance of careful evaluation of controller designs is stressed. The use of simulations and data trials is discussed. The simulation result indicates that compared with the flicker coefficient of PI controlled wind turbine, the variable-speed wind turbines equipped with individual pitch controller, exhibit good behavior with respect to output power and voltage flicker, especially for $3 \mathrm{P}$ frequency reduction. Thereby, the variable-speed wind turbine with individual pitch controller will produce lower voltage flicker.

\section{THE MODEL SYSTEM OF WIND TURBINE}

The wind turbine model includes electrical, mechanical and aerodynamic models [8]. Fig. 1 illustrates the overall structure of the wind turbine model.

It consists of an aerodynamic, a mechanical and an electrical model, with a blade angle control model for power regulation. The wind model provides an equivalent wind speed $\mathrm{V}_{\text {eq }}$ as input to the aerodynamic model. The equivalent wind 
speed $\mathrm{V}_{\text {eq }}$ takes into account the rotational turbulence, the tower shadow and the variations in the whole wind speed field over the rotor disk, by using the information from the generator speed $\omega_{\text {gen }}$. Besides the equivalent wind speed $V_{\text {eq }}$, the pitch angle $\theta_{1}, \theta_{2}, \theta_{3}$ from the control system and the wind speed constitute the inputs of the aerodynamic model. The output of the aerodynamic model is the aerodynamic power $\mathrm{P}_{\mathrm{ae}}$, which is input for the mechanical model together with the generator speed $\omega_{\text {gen }}$. The mechanical model delivers the mechanical power $\mathrm{P}_{\mathrm{G}}$ to the generator model.

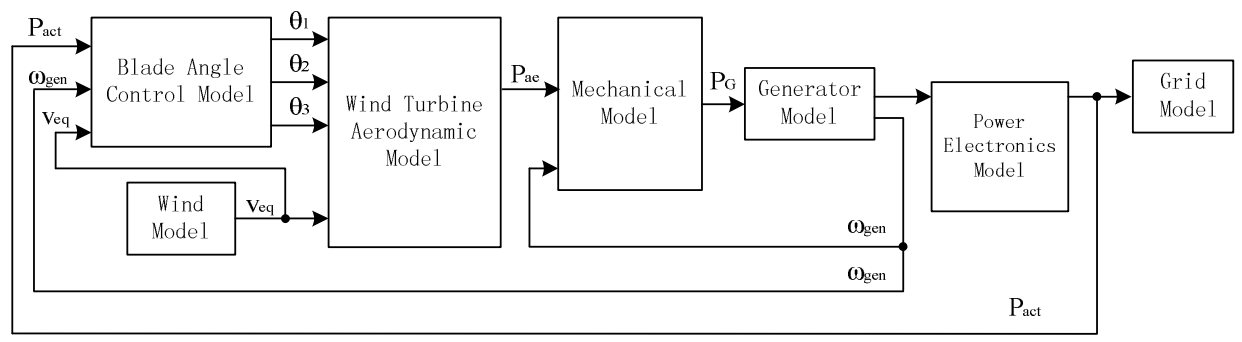

Fig.1 Simulation flow of the wind turbine model

\section{A. Wind model}

The wind model is built of two types of effects, namely deterministic effects and stochastic effects. The deterministic part of the wind model contains the mean wind speed and tower shadow variations. The stochastic part of the wind model includes the effects of the rotational turbulence, namely that turbulence caused by the rotating wind turbine blades.

Only the horizontal component of the wind speed is considered in the model. The rotational turbulence and the tower shadow are included in the model as they have a major impact on power fluctuation with three times the rotational frequency (3P), which is the frequency that mainly contributes to flicker emission during continuous operation. The tower shadow is modeled as a 3P fluctuation with constant amplitude, Whereas the rotational sampled turbulence is modeled as a $3 \mathrm{P}$ fluctuation with variable (stochastic) amplitude [8].

\section{B. Wind turbine model}

Approaches to simplified aerodynamic modeling of wind turbines have been presented in [9] and [10]. The main idea in these papers is to adjust wind speed data in one point (hub level) by various filters in order to represent the interaction of turbine blades with the wind speed distribution over the rotor swept area. The present aerodynamic model is based on the aerodynamic efficiency $C_{p}(\theta, \lambda)$, which is calculated by a standard aerodynamic program. This simplification is acceptable as long as only the effect on the aerodynamic power $\mathrm{P}_{\mathrm{ae}}$, is taken into account. For a given rotor, $\mathrm{C}_{\mathrm{p}}(\theta, \lambda)$ depends on the pitch angle $\theta$ and on the tip speed ratio $\lambda$. The aerodynamic efficiency, usually tabled as a matrix in the aerodynamic program, is used to determine the quasi static aerodynamic power $\mathrm{P}_{\mathrm{ae}}$ developed on the main shaft of a wind turbine with rotor radius $R$ at a wind speed $V_{\text {eq }}$ and air density $\rho$ :

$$
P_{a e}=\frac{1}{2} \rho \pi R^{2} V_{e q}^{3} C_{p}(\theta, \lambda)
$$

The simplification of using a steady state aerodynamic efficiency, instead of a dynamic aerodynamic efficiency, in (1) corresponds to the steady state aero loads. This simplification underestimates the actual power fluctuations in the stall region.
Study indicates the power curve of a wind turbine and how large the power fluctuations are, as caused by wind speed fluctuations for two situations: low wind speed area which is below $8 \mathrm{~m} / \mathrm{s}$ and high wind speed area which is above $8 \mathrm{~m} / \mathrm{s}$. For low wind speeds there is no significant difference between the static power and the dynamic power, because the amplification factors of the fluctuations for both steady state and dynamic state are similar. This is not the case for the high wind speeds in the stall region, where, due to the dynamic stall effects, fluctuations in wind speed, produce larger power fluctuations. However, the voltage fluctuation and flicker might catch the severe value during wind speed at $6-10 \mathrm{~m} / \mathrm{s}$. Therefore, wind speed simulation value is around $7 \mathrm{~m} / \mathrm{s}$, and simplified aerodynamic modeling for wind turbines is selected.

For the direct coupled low-speed generators, PSCAD/EMTDC provides a fully developed synchronous machine model, based on the generalized machine theory [11]. Vector-control technology has been developed for direct-drive generators using back-to-back PWM converters [12]. Since the study interest is not concentrated on the switches of the PWM converter but for the flicker calculation that requires a long simulation time, an average model without switches is used so that the simulation can be carried out with a larger time step resulting in a simulation speed improvement [13].

\section{Classical designs of PI controller}

PI (proportional and integral) and PID (proportional, integral and derivative) controllers are widely used throughout industry and are a good starting point for many wind turbine control applications. A PID controller can be written in terms of the Laplace variable s(similar to a differentiation operator) as

$$
y=\left(\frac{K_{i}}{s}+K_{p}+\frac{K_{d} s}{1+s \tau}\right) x
$$

Where $\mathrm{x}$ is the input error signal to be corrected and $\mathrm{y}$ is the control action. $\mathrm{K}_{\mathrm{i}}, \mathrm{K}_{\mathrm{p}}$ and $\mathrm{K}_{\mathrm{d}}$ are the integral proportional and derivative gains. The time constant $\tau$ prevents the derivative term from becoming large at high frequency, where it could respond excessively to signal noise. $K_{d}$ is zero in a PI controller. 


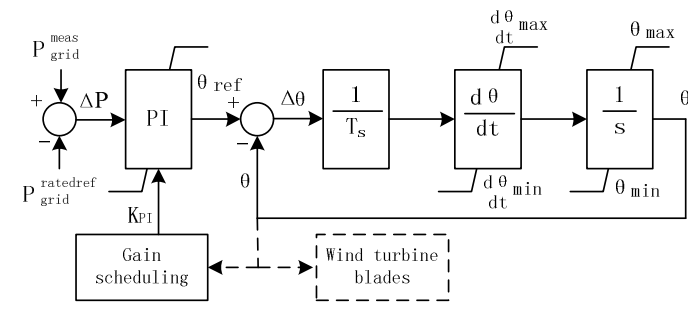

Fig.2 The power limitation control loop

Fig. 2 shows the power limitation control loop. The power limitation controller has as task to increase or decrease the pitch angle in the power limitation strategy, i.e. in order to limit the generated power to the rated power. The error signal $\Delta \mathrm{P}$ based on the measured power in the grid point, is sent to a PIcontroller. The PI controller produces the reference pitch angle $\theta_{\text {ref. }}$ This reference is further compared to the actual pitch angle $\theta$ and then the error $\Delta \theta$ is corrected by the servomechanism. In order to get a realistic response in pitch angle control system, the servomechanism model accounts for a time constant $T_{\mathrm{s}}$ and the limitation of both the pitch angle and its gradient. The output of the power limitation controller is the pitch angle of the blades.

\section{Individual pitch controller}

The wind speed variations over the rotor disc result in a large once-per-revolution, or 1P, component in the blade loads, together with harmonics of this frequency, i.e. $2 \mathrm{P}, 3 \mathrm{P}, 4 \mathrm{P}$ and so on. With a three-bladed rotor these load components will be $120^{\circ}$ out of phase between the three blades, with the result that the hub and the rest of the structure will experience the harmonics at $3 \mathrm{P}, 6 \mathrm{P}$, etc. The design of the control algorithms is clearly of prime importance. By controlling the pitch of each blade independently, it is also possible to achieve important further reductions in loading and $3 \mathrm{P}$ fluctuation.

In recent years research has been done in this area by Bossanyi [5]. Bossanyi's method is based on measurement of blade root loads and transforming them into a mean value and variations on two orthogonal axis using "dq axis transformation". The two orthogonal axes are known as quadrature axes and the transformation matrix that transforms the rotating blades to quadrature axes is given by (3)

$$
\left(\begin{array}{l}
\beta_{d} \\
\beta_{q}
\end{array}\right)=\left(\begin{array}{cc}
2 / 3 & 0 \\
0 & 2 / 3
\end{array}\right)\left(\begin{array}{ccc}
\cos (\theta) & \cos (\theta+2 \pi / 3) & \cos (\theta+4 \pi / 3) \\
\sin (\theta) & \sin (\theta+2 \pi / 3) & \sin (\theta+4 / 3)
\end{array}\right)\left(\begin{array}{l}
\beta_{1} \\
\beta_{2} \\
\beta_{3}
\end{array}\right)
$$

It is assumed that there is no interaction between the two axes. To overcome the time-delay caused while measuring the blade loads Bossanyi introduces a phase shift in the modulated feedback signals of $\beta_{\mathrm{d}}$ and $\beta_{\mathrm{q}}$, such that the 'around-1p' variation in the three pitch angles is obtained by modulation of the feedback $\beta_{\mathrm{d}}$ and $\beta_{\mathrm{q}}$ with azimuth angle is $\theta+\Delta \theta$, where $\Delta \theta$ compensates for actuator delay. The authors have implemented a PI based feedback control of pitch angle based on the error between the angle of attack of a single blade and average angle of attack. For relative velocity based control action, a feed forward gain is calculated and implemented as given in (5).

$$
\begin{aligned}
& V_{e q}=V_{r e l} \cos (\alpha+\theta) \\
& \theta_{i, b}=\left(V_{e q}-V_{e q, a v g}\right) K\left(\omega, \theta_{\text {coll }}\right)
\end{aligned}
$$

Where $\mathrm{V}_{\mathrm{eq}}$ is the wind speed in-plane with the rotor which is a function of relative velocity or rotor centric velocity $V_{\text {rel }}$, blade pitch angle $\theta$ and angle of attack $\alpha, V_{\text {eq }}-V_{\text {eq,avg }}$ is the error between the in-plane relative velocity on the single blade and the average in-plane relative velocity of the three blades and $K\left(\omega, \theta_{\text {coll }}\right)$ is the feed forward gain function. The gain function is based on calculations of skew inflow with the turbine equipped with a cyclic pitch regulator.

\section{E. Short term flicker severity}

Flicker is defined as an impression of unsteadiness of visual sensation induced by the light stimulus whose luminance or spectral distribution fluctuates with time' and it is related to voltage and, in turn, power fluctuations. The intensity of these emissions, which people find disturbing (especially for fluctuations around $9 \mathrm{~Hz}$ ) and may also cause unwanted heating of electrical components connected to the network, is estimated through the short-time flicker severity index, $\mathrm{P}_{\text {st. }}$ It is seen that the flicker emission from a single wind turbine at the PCC is given by:

$$
C\left(\varphi_{k}, V_{a}\right)=P_{s t, f i c} \cdot S_{n, f i c} / S_{n}
$$

Where $C\left(\varphi_{k}, V_{a}\right)$ denotes flicker coefficient of the wind turbine for given network impedance phase angle $\varphi_{\mathrm{k}}$ at the point of common coupling (PCC), and for given annual average wind speed $V_{a}$ measured at the hub-height of the wind turbine, $\mathrm{S}_{\mathrm{n}, \mathrm{fic}}$ is the short circuit apparent power of fictitious grid, $S_{n}$ denotes the rated apparent power of wind turbine. $P_{\text {st.fic }}$ is the voltage flicker of fictitious grid modeled by simulated data.

The flicker severity caused by continuous operation of a single WT can be calculated according to following expression

$$
P_{s t}=C\left(\varphi_{k}, V_{a}\right) \cdot S_{n} / S_{k}
$$

Flicker coefficient $C\left(\varphi_{k}, V_{a}\right)$ is calculated by $(5) . \mathrm{S}_{\mathrm{k}}$ is the short circuit capacity of the point of common coupling, $S_{n}$ denotes the rated apparent power of wind turbine.

\section{SIMULATION RESULT}

The model parameters pertain to a typical $1.5 \mathrm{MW}$ wind turbine with $36 \mathrm{~m}$ rotor radius $\mathrm{R}_{\mathrm{b}}$. The parameters were determined for average wind speed of $7.5 \mathrm{~m} / \mathrm{s}$, rotor speed to $15 \mathrm{rpm}$ and pitch angle of $10^{\circ}$. Time-domain simulations were performed with the controlled model. These simulations will be run with the collective pitch controller, and repeated with addition of the individual pitch control action.

The wind signal used in the simulation is as shown in Figure 3. A set of 10-minute Bladed turbulent wind simulations at several mean wind speeds will be set up. Figure 4 is the active power with collective pitch controller and Figure 5 is the active power with individual pitch controller. 


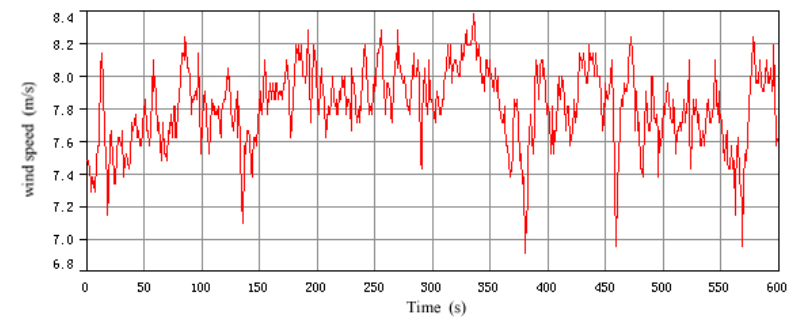

Fig.3 Wind speed signal used in the simulation

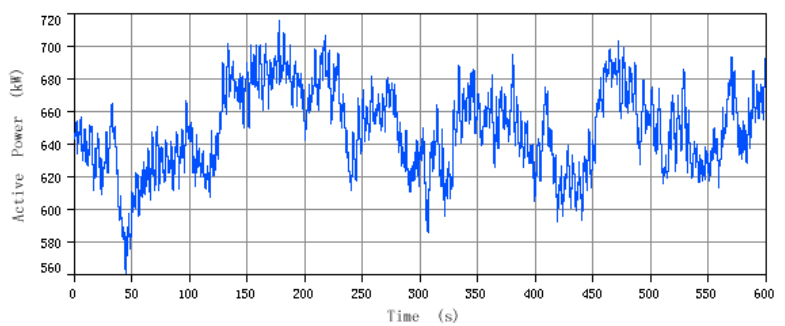

Fig.4 Active power using PI pitch controller

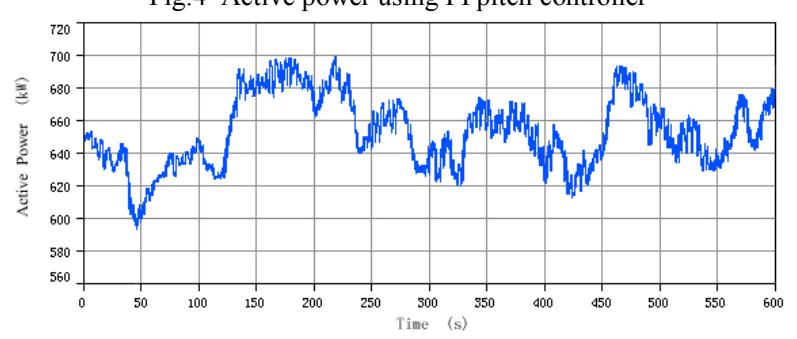

Fig.5 Active power using individual pitch controller

For the wind turbines connected to the transmission networks, the flicker contribution from the wind turbines in the connection point shall be limited to be below $\mathrm{P}_{\mathrm{st}}=0.35$ is considered acceptable for wind turbine installations [14]. The variation of short-term flicker severity $\mathrm{P}_{\mathrm{st}}$ with wind speed for two situations is illustrated as follows: $P_{\text {st,indivual }}=0.05$, and $\mathrm{P}_{\text {st, collective }}=0.12$.

\section{CONCLUSION}

Compared with the flicker coefficient of PI controlled wind turbine, it appears obviously that the variable-speed wind turbines, equipped with individual pitch controller, exhibit good behavior with respect to output power and voltage flicker. As it is shown, the flick emission values from both controller are belong the limitation of power quality required for wind turbine. The $\mathrm{P}_{\mathrm{st}}$ value controlled by individual pitch controller is lower than the collective one. The reason is that the pitch regulation of each blade could reduce the $3 \mathrm{P}$ fluctuation and smooth out the power fluctuations of wind turbine. Thereby, the variable-speed wind turbine with direct-drive generator will produce lower voltage flicker.

For variable speed turbines, attention to detail in the interaction of pitch and torque controllers can significantly improve energy capture. Individual pitch control has potential for very significant $3 \mathrm{P}$ frequency reduction but is not yet commercially proven. This behavior is related to control laws can help attain global objectives such as power quality improvement and load reduction, which have to be considered when establishing the design specifications of the control algorithm. Thus, advanced controller design methods can offer an explicit mathematical formulation for the design of controllers with multiple objectives, including flicker reduction.

\section{ACKNOWLEDGMENT}

At the end of this paper, I would like to thank all those people who made this paper possible. First of all I wish to express my sincere gratitude to Prof. Weiqing Wang, who guided this work and helped whenever I was in need. I am grateful to Mr. Liang Bin and Mr. Haitao $\mathrm{He}$ for their support during the modeling and simulating processing. Finally I would express my deepest gratitude to the Xinjiang Goldwind Science \& Technology CO., ltd for its support.

\section{REFERENCES}

[1] Eltra: Specifications for connecting wind farms to the transmission network. ELT 1999-411a, 2000, http://www.eltra.dk.

[2] IEC 61400-21 (2001). Wind turbine generator systems - Part 21: Measurement and assessment of power quality characteristics of grid connected wind turbines.

[3] Hansen, L.H.,Helle L., Blaabjerg F., Ritchie E., et al. : Conceptual survey of Generators and Power Electronics for Wind Turbines, RisøR-1205(EN).2001

[4] T.G. van Engelen, D. Winkelaar, H. Markou (Risø), et al.: Morphological Study of Aeroelastic Control Concepts for Wind Turbines, StabCon Task-7 Report, 2006.5, ECN Wind Energy, Petten, the Netherlands

[5] Bossanyi E: Individual blade pitch control for load reduction. Wind Energy 2003.6,pp:119-128

[6] T.G. van Engelen, E.L. van der Hooft: Individual Pitch Control, Inventory; Technical Report ECN-C-03-138, ECN Wind Energy, ECN Petten, the Netherlands.

[7] Bossanyi: Developments in Individual Blade Pitch Control; in Proceedings of special topic conference on the Science of Making Torque from Wind, pp. 486-497, Delft, the Netherlands, April 2004

[8] T.G. van Engelen, E.L. van der Hooft: Dynamic Inflow Compensation for Pitch Controlled Wind Turbines; in Proceedings of European Wind Energy Conference in London, UK, 2004.

[9] Hansen A. D., Sørensen P., Blaabjerg F., Bech J.: Dynamic modelling of wind farm grid interaction. Wind Engineering, Vol. 26, No.4, pp:191-208, 2002.

[10] Tomas Petru, Torbjorn Thiringer: Modeling of Wind Turbines for Power System Studies, IEEE Trans. Energy Conversions, Vol 17, No. 4, pp.1132-1139, Nov. 2002

[11] PSCAD User's Guide, Manitoba HVDC Research Centre Inc., Winnipeg, MB, Canada, 2003.

[12] Seul-Ki Kim, Eung-Sang Kim: PSCAD/EMTDC-Based Modeling and Analysis of a Gearless Variable Speed Wind Turbine, IEEE Transactions on Energy Conversion, vol. 22 no. 2, pp:421-430, June 2007.

[13] P. Giroux, G. Sybille, and H. Le-Huy: Modeling and simulation of a distribution STATCOM using simulink's power system blockset, in Proc. 27th Annual Conference IEEE Industrial Electronics Society, vol. 2, Denver, CO,USA, Nov. 29-Dec. 2, 2001, pp:990-994.

[14] ELTA: Transmission System Planning, Specifications for Connecting Wind Turbines to Low and Medium Voltage Networks, $2^{\text {nd }}$ ed., Research Institute for Danish Electric Utilities(DEFU), October 1998. 